\title{
Assessment of knowledge, attitudes and practices towards prevention of coronavirus disease (COVID-19) among Bangladeshi population
}

\author{
Rahman $\mathrm{SMM}^{1 *}$, Akter A ${ }^{1}$, Mostari KF ${ }^{1}$, Ferdousi $\mathrm{S}^{2}$, Ummon IJ ${ }^{3}$, Naafi $\mathrm{SM}^{4}$, Rahman $\mathrm{MM}^{5}$, Uddin MGMN ${ }^{6}$, \\ Tasmin $\mathrm{S}^{1}$, Uddin MA ${ }^{1}$, Lopa SAK ${ }^{1}$, Amin SMS ${ }^{7}$, Miah MAR $^{8}$, Saha TK ${ }^{9}$, Rahim MA $^{9}$, Hossain SM ${ }^{10}$ \\ ${ }^{I}$ Academic Wing, Institute of Public Health, Dhaka, Bangladesh; ${ }^{2}$ Microbiology Lab, Institute of Public \\ Health, Dhaka, Bangladesh; ${ }^{3}$ Disease Control Unit, Directorate General of Health Services, Dhaka, \\ Bangladesh; ${ }^{4}$ Dhaka Medical College and Hospital, Dhaka, Bangladesh; ${ }^{5}$ Civil Surgeon Office, Rangpur, \\ Bangladesh; ${ }^{6}$ Upazila Health Complex, Shahjahanpur, Bogura, Bangladesh; ${ }^{7}$ Bangladesh Medical \\ Research Council, Dhaka, Bangladesh; ${ }^{8}$ Health Services Division, Ministry of Health and Family Welfare, \\ Dhaka, Bangladesh; ${ }^{9}$ Institute of Public Health, Dhaka, Bangladesh; ${ }^{10}$ Former Director General of Health \\ Services, Dhaka, Bangladesh
}

\begin{abstract}
Background: Cornonavirus disease (COVID-19) has been declared pandemic by the World Health Organization on the $11^{\text {th }}$ March 2020. The knowledge, attitudes and practices of the population towards the COVID-19, play an integral role in determining community's readiness to engage themselves in government measures including behavioural change in prevention and control of the disease.

Objectives: The study was aimed to determine the knowledge levels, attitudes and practices towards the COVID-19 among the Bangladeshi population.

Methods: A cross sectional study was conducted among 1549 adult population across Bangladesh including Dhaka city and rural areas during March-April 2020. Data were collected using a structured and pretested questionnaire through online, self-administered and face to face interview. The study instrument consisted of 7 items on socio-demographic characteristics, 12 items on knowledge, 4 items on attitudes and 5 items on practices related to COVID-19. Independent sample t-tests, chi-square tests, one-way analysis of variance (ANOVA) and binary logistic regression were performed to assess the attitudes and practices in relation to knowledge.

Results: Of the total 1549 study population, 1249 were interviewed online, 194 were self-administered and 106 were through face to face interview. The lowest level of knowledge prevailed among the above 50 years' age group regarding the disease, which was higher among female $(p=0.03)$, and more among the respondents having education level below graduation $\left(p=0.000 ; \mathrm{OR}=1.6, \chi^{2}=17.6\right)$. Of the total respondents, $73.5 \%$ having negative attitude towards use of face mask, though $69.8 \%$ having the appropriate knowledge on mode of transmission of the virus $(p=0.000)$. Though, $51.6 \%$ of the study population, having adequate knowledge, but only $52.1 \%$ using face mask $(p>0.05)$ and $51.8 \%$ practicing hand washing $(p>0.05)$. More than $70.0 \%$ respondents having knowledge on social distancing, but only $50.0 \%$ was practicing it. Male respondents had 1.5 times more knowledge about the social distancing than the female counterpart $(p=0.000)$.

Conclusion: Public awareness campaign should be enhanced critically focusing the target audience covering the knowledge gaps, motivation for appropriate practices and further improvement of attitudes towards prevention and control of COVID-19 in Bangladesh thus suggested.
\end{abstract}

Keywords: COVID-19, Social distancing, Stigma, Knowledge deficit

\section{Introduction}

Coronavirus disease (COVID-19) is an infectious disease caused by the most recently discovered coronavirus SARS-CoV-2, a member of a family of viruses that usually cause respiratory illness. It was unknown before the outbreak began in Wuhan, China, in December 2019. ${ }^{1,2}$ The outbreak was linked

*Correspaondence: Dr Shah Md Mahfuzur Rahman, Academic Wing, Institute of Public Health, Dhaka, Bangladesh; email: smahfuzbd@gmail.com; ORCID: 0000-0002-5069-6718 epidemiologically to the Hua Nan seafood and wet animal wholesale market in Wuhan, and the market was subsequently closed on 1 January $2020 .^{3}$ The virus rapidly spread to all provinces in China, as well as a number of countries across the globe, and was declared a Public Health Emergency of International Concern by the Director General of the World Health Organization on 30 January $2020 .^{2}$ On 11 March 2020, the WHO declared COVID-19 a pandemic., ${ }^{4,5}$ 
Human-to-human transmission of SARS-CoV-2 has been widely shown in health care, community and family settings. ${ }^{3}$ Primarily, it spreads from person to person by close contact through small droplets of saliva or discharge from the nose, when an infected person coughs sneezes or exhales. The respiratory droplets from the infected person fall on the ground or objects or surfaces around the person. Other people then infected by touching these objects or surfaces, that the virus on it, then touching their eyes, nose or mouth. ${ }^{6}$ Based on the epidemiological investigations, the incubation period of the SARS-CoV-2 is between 1-14 days and the virus has been found to be contagious in the asymptomatic patients. ${ }^{7}$

The most common symptoms of COVID-19 are fever, dry cough, and tiredness. Other symptoms that are less common and may affect some patients include aches and pains, nasal congestion, headache, conjunctivitis, sore throat, diarrhea, loss of taste or smell or a rash on skin or discoloration of fingers or toes. These symptoms are usually mild and begin gradually. Some people become infected but only have very mild symptoms. About $80.0 \%$ of COVID-19 patients recover from the disease without any hospitalisation. Approximately $20.0 \%$ of infected cases had a severe illness such as shortness of breath, septic shock and multi-organ failure, and it has been reported that an estimated $2.0 \%$ of cases can be fatal. ${ }^{8}$ Older people, and those with underlying medical problems like high blood pressure, heart and lung diseases, diabetes, or cancer, are at higher risk of developing serious illness. ${ }^{1,9}$ People infected with SARS-CoV-2 may not have the symptoms, but can transmit the virus. ${ }^{1}$ The CDC estimates asymptomatic cases are 75 percent as infectious as symptomatic ones, but the agency cautions that this assumption is based on a murky understanding of what's known as "viral shedding," in which people unknowingly release contagious virus into the atmosphere. ${ }^{10}$

Currently, there is no specific antiviral treatment and preventive vaccine. This unprecedented global crisis has also been marked by miscommunication regarding the imminent threat of COVID-19, leading to public confusion and inaction. ${ }^{11}$

Therefore, the guidelines are recommended to decline the spread of infection and respond to the challenges during the epidemic. ${ }^{12}$ The best way to prevention is to avoid being exposed to infection. This is can be carried out by washing hands with soap and water frequently and thoroughly, use hand sanitser and using face masks, maintain respiratory hygiene, maintaining social distancing (at least one metre physical distance from others, isolating confirmed and suspected cases. ${ }^{1,6,8}$ Furthermore, people who are not ill themselves but may have been exposed to COVID-19, should be quarantined- restricting activities or separating for period of 14 days, from the last day of the exposure, and people who are ill with symptoms of COVID-19 and may be infectious or positive test should be isolated.

For this, every individual should be equipped with knowledge, motivated for positive attitudes and translate it into practices, which is very much essential for containment of the COVID-19 pandemic. Health literacy has emerged over the past 3 decades as one of the strongest psychosocial determinants of health, and it has also been shown to explain a range of health disparities by age, race/ethnicity, and socioeconomic status. 13 Thus, in uncertain times like this, when the interpretation of critical and ever-changing public health messages is paramount, many vulnerable populations may be further marginalized by inadequate health communication, posing substantial risks to themselves and their

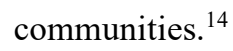

This study was aimed to assess the knowledge, attitudes and practices among the Bangladeshi population towards COVID-19 prevention and control. It is expected that the information to be generated through this study will be insightful, and broadly useful in the planning for public awareness campaign in COVID-19 prevention and control.

\section{Materials and Methods}

Study type and period: This cross-sectional study was conducted among the adult population across Bangladesh including Dhaka city and two rural areas in northern part of the country during MarchApril, 2020.

Study population: Of the total 1549 study population, 1249 were interviewed online, 194 
were self-administered and 106 were face to face interviewed. Participants belong to adult population live in the country, good physical and mental condition (in case of self-administered and face to face interview), who agreed to participate, were included in the study. Exclusion criteria included unwillingness and sickness.

Sample size and sampling technique: Considering the special situation, it could not be possible to conduct a fully community based study with a nationally representative sample. In the rural areas a random sampling technique was adopted to obtain the sample. But in apartment buildings, questionnaire sets were distributed to all apartments. But the response rate was $72.7 \%$.

Data collection: The data were collected using a structured questionnaire, except the place of residence under which Upazila or Thana. The questionnaire was in Bangla. It was pre-tested among a cross section of participants to ensure the clarity of questions and eliminate the ambiguity. The online part of this study was conducted (as requested) amongst a subsample of Bangladeshi citizen and live in the country. To contact the online interviewees, a request letter containing the objectives of the study and the confidentiality issues was posted on the social media-Facebook with a link of the questionnaire. The authors' social media network including other platform like messenger, WhatsApp and Viber were used.

Another sub sample of the study population was interviewed using the questionnaire as self-administered in two large apartment buildings in Dhaka city. The Questionnaire was distributed and collected through the care taker of the buildings, during his routine visit (as part of duties) of the apartments. It has been asked not make duplication if he or she already responded over online. In such case, to avoid duplication other family member was requested to response.

The third sub sample of the study population in rural villages of Rangpur and Bogura was interviewed by the two authors through face to face interview in two rural areas in northern part of the country maintaining social distance, wearing face masks and other hygienic measures.
The questionnaire was designed/constructed to collected socio-demographic characteristics including gender, age, education, occupation, religion and monthly income of all participants. The other variables such as knowledge, attitudes and practices related to coronavirus (COVID-19) infections and its prevention and control. The knowledge was assessed by 11 factual statements included in the questionnaire such as about the disease, its nature and mode of transmission, high risk population, symptoms of the disease, availability of vaccines, specific treatment, preventive measures, quarantine period, social distancing and incubation period. The attitude parameters included effectiveness of mask use, hand washing and social distancing in preventing the disease. The practice parameters included use of mask, frequency of hand washing and use of sanitiser and maintaining social distancing.

Based on the $80-100 \%$ correct answer for each question was considered as appropriate knowledge, and below $80.0 \%$ was considered as inappropriate knowledge. Similarly, attitudes and practices were also categorised.

At the very outset of the interview, the respondents were informed adequately about the purpose of the study, as well as he or she deserved the rights to participate or nor, or even participate, could withdraw himself or herself at any point of participation. The consent was obtained either online before starting the answer of the question or written in case of self-administered or those can read or write or verbal for those as few were illiterate. Approval of the study protocol and procedures and ethical clearance were obtained from the Institutional Review Board of the Institute of Public Health, Dhaka.

Data analysis: Collected data were cross-checked and cleaned. Descriptive statistics including percentages, means, and standard deviations were calculated. Attitudes and practices in relation to knowledge were assessed with independent samples $\mathrm{t}$ test, one-way analysis of variance (ANOVA) or Chi-square test as appropriate.

To identify the factors associated with knowledge, multivariable linear regression analysis was 
performed, using all of the demographic variables as independent variables and knowledge status as the outcome variable. To identify factors associated with attitudes and practices, binary logistic regression analyses were performed, selecting the factors with a backward stepwise method.

To quantify the associations between variables and knowledge, attitudes and practices, unstandardised regression coefficients $(\beta)$ and odds ratios (ORs) were performed.

Statistical significance was set to 0.05 or less and a confidence interval of $95 \%$ for all analyses.

Data entry and statistical analyses were performed using Statistical Package for Social Science Programme for Windows (Version 23.0).

\section{Results}

A total of 1549 participants were interviewed in this cross-sectional study. Of them, 897 (57.9\%) were male, $646(41.7 \%)$ were female and $6(0.4 \%)$ were transgender (figure1).

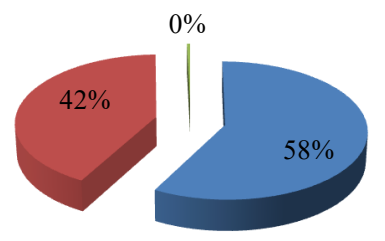

- Male

- Female

$\square$ Transgender

Figure-1: Gender distribution of respondents ( $\mathrm{n}=1549)$

Among the total study population $1549,87.9 \%$ were from cities followed by $6.8 \%$ from villages, $2.8 \%$ from Upazila towns, $2.5 \%$ from district towns and (figure 2).

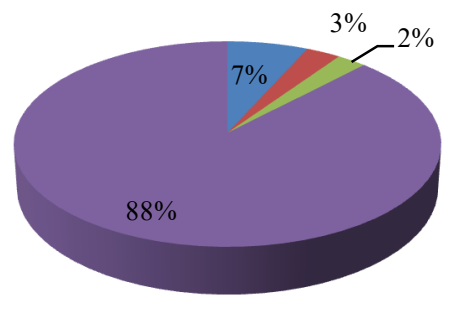

- Village

- Upazilla

District

- City

Figure-2: Geographical distribution of the respondents $(\mathrm{n}=1549)$
It may be mentioned here, of the total 1249 online respondents, $60.5 \%$ were from cities, $17.0 \%$ from villages, $11.7 \%$ from Upazila towns and $10.6 \%$ from the district towns (figure 3).

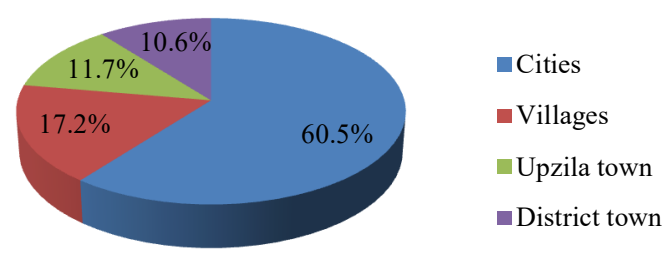

Figure-3: Geographical distribution of the online study population $(\mathrm{n}=1249)$

Of the study population, $28.4 \%$ belonged to $36-50$ years age group (Figure 4 ).

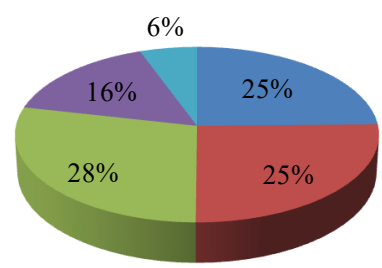

$$
\begin{aligned}
& =18-25 \text { years } \\
& \square \text { 26-35 years } \\
& \square \text { 36-50 years } \\
& \square \text { 51-60 years } \\
& \square 61-\text { above years }
\end{aligned}
$$

Figure-4: Distribution of age of the study population

$30.0 \%$ completed their graduation degree, and $29.0 \%$ were students, $16.2 \%$ were housewives and $9.5 \%$ were unemployed (figure 5 ).

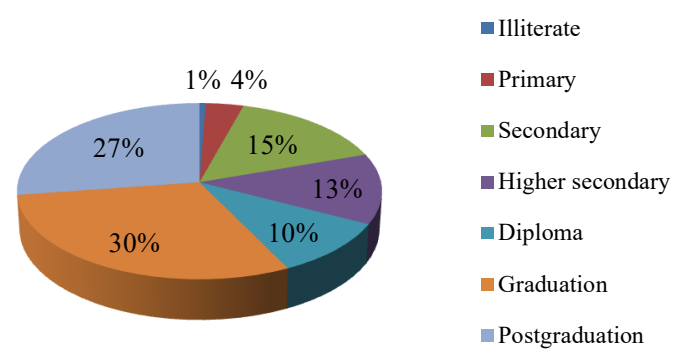

Figure-5: Educational levels of the study population

Furthermore, regarding the inadequate knowledge, 36 and above age group knew lesser about the symptoms of the disease than other age group, 


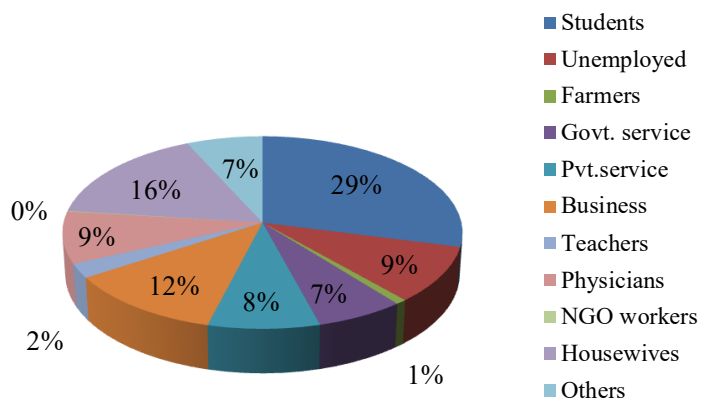

Figure 6: Distribution of profession of Respondents ( $\mathrm{n}=1549)$

50 years and above age group having lowest level of knowledge regarding the nature of the disease, which was higher among female respondents ( $p=0.03$ ), and more prevalent among respondent having education level below graduation $(p=0.000$; $\mathrm{OR}=1.6, \chi^{2}=17.6$ )

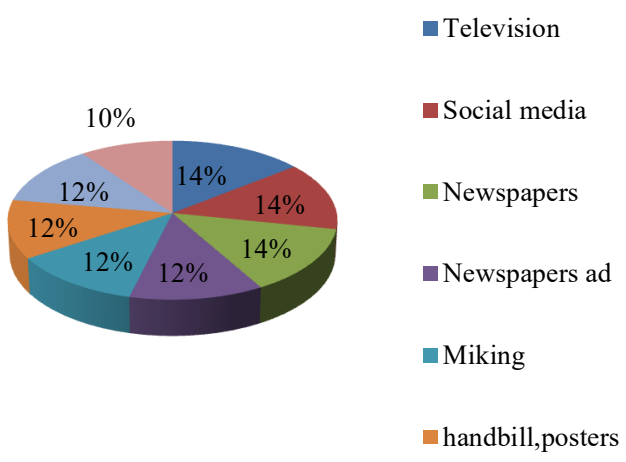

Figure 7: Sources of Knowledge

Education level did not having any significant influence on the knowledge on how the COVID-19 spreads, preventive measures and social distancing (table I).

Table-I: Assessment of knowledge $(\mathrm{n}=1549)$

\begin{tabular}{|c|c|c|c|c|c|}
\hline \multirow{2}{*}{$\begin{array}{l}\text { No. } \\
1\end{array}$} & \multirow{2}{*}{$\begin{array}{r}\text { Area of knowledge } \\
\text { Common symptoms of Covid-19 }\end{array}$} & \multicolumn{2}{|c|}{$\begin{array}{c}\text { Appropriate knowledge } \\
\text { f (\%) }\end{array}$} & \multicolumn{2}{|c|}{$\begin{array}{c}\text { Inappropriate knowledge } \\
\text { f (\%) }\end{array}$} \\
\hline & & 87 & $(5.8)$ & 1412 & $(94.2)$ \\
\hline 2 & Nature of the COVID-19 & 392 & $(26.2)$ & 1107 & $(73.8)$ \\
\hline 3 & Population high risk to COVID-19 & 1324 & $(88.3)$ & 175 & $(11.7)$ \\
\hline 4 & $\begin{array}{l}\text { Availability of specific treatment for the } \\
\text { COVID-19 }\end{array}$ & 1415 & $(94.4)$ & 84 & $(5.6)$ \\
\hline 5 & Availability of vaccine against the Covid- 19 & 1327 & $(88.5)$ & 172 & $(11.5)$ \\
\hline 6 & Mode of transmission of Covid-19 & 1047 & $(69.8)$ & 452 & $(30.2)$ \\
\hline 7 & $\begin{array}{l}\text { Preventive measures against the contract of the } \\
\text { coronavirus }\end{array}$ & 773 & $(51.6)$ & 726 & $(48.4)$ \\
\hline 8 & $\begin{array}{l}\text { Duration of handwashing necessary for } \\
\text { preventing the COVID-19 }\end{array}$ & 56 & $(3.7)$ & 1443 & $(96.3)$ \\
\hline 9 & Knowledge on social distancing & 1086 & $(72.4)$ & 413 & $(27.6)$ \\
\hline 10 & Knowledge on home quarantine & 721 & $(48.1)$ & 778 & $(51.9)$ \\
\hline 11 & $\begin{array}{l}\text { Importance of } 14 \text { days period in case of home } \\
\text { quarantine }\end{array}$ & 1281 & $(85.5)$ & 218 & $(14.5)$ \\
\hline
\end{tabular}

Attitudes towards prevention of the disease were assessed through four questions. Of them, of thought that the use of face mask some extent $78.4 \%$ having positive attitude towards the use face mask when someone is outside, $63.3 \%$. 
Table-II: Assessment of attitudes towards prevention of Corona infection ( $\mathrm{n}=1499)$

\begin{tabular}{|c|c|c|c|c|}
\hline No & $\begin{array}{c}\text { Question } \\
\text { about } \\
\text { Attitude }\end{array}$ & $\begin{array}{c}\text { Positive } \\
\text { attitude } \\
\text { f }(\%)\end{array}$ & $\begin{array}{c}\text { Negative } \\
\text { attitude } \\
\text { f }(\%)\end{array}$ & $\begin{array}{c}\text { Unaware } \\
\text { f (\%) }\end{array}$ \\
\hline 1 & $\begin{array}{l}\text { Does everyone } \\
\text { need to use } \\
\text { mask? }\end{array}$ & $\begin{array}{c}1175 \\
(78.4)\end{array}$ & $\begin{array}{c}209 \\
(13.9)\end{array}$ & $115(7.7)$ \\
\hline 2 & $\begin{array}{l}\text { Does use of } \\
\text { mask effective } \\
\text { for prevention } \\
\text { of Corona? }\end{array}$ & $\begin{array}{c}949 \\
(63.3)\end{array}$ & $113(7.5)$ & $\begin{array}{c}437 \\
(29.2)\end{array}$ \\
\hline 3 & $\begin{array}{l}\text { Does hand } \\
\text { washing } \\
\text { prevent corona } \\
\text { infection? }\end{array}$ & $\begin{array}{c}1313 \\
(87.6)\end{array}$ & $40(2.7)$ & $146(9.7)$ \\
\hline 4 & $\begin{array}{l}\text { Does social } \\
\text { distancing play } \\
\text { role in } \\
\text { preventing } \\
\text { corona? }\end{array}$ & $\begin{array}{c}1390 \\
(92.7)\end{array}$ & $3(.2)$ & $106(7.1)$ \\
\hline
\end{tabular}

Practices for the prevention of the Covid-19 were assessed through five questions. Most of the respondents had appropriate practices including use of mask (83.5\%), use of hand sanitizer (83.1\%), frequency of handwashing (70.2\%). But almost half of respondents did not have appropriate practices for use of hand sanitizer. Only thirty five percent respondents performed appropriate practices which include use of face mask, hand washing and maintenance of social distancing, aimed to prevent corona infection (table-III).

Table-III: Assessment practices against contract with Coronavirus $(\mathrm{n}=1549)$

\begin{tabular}{clcc}
\hline No & $\begin{array}{c}\text { Question } \\
\text { about } \\
\text { practice }\end{array}$ & $\begin{array}{c}\text { Appropriate } \\
\text { practice } \\
\text { f (\%) }\end{array}$ & $\begin{array}{c}\text { inappropriate } \\
\text { practice } \\
\text { f (\%) }\end{array}$ \\
\hline 1 & $\begin{array}{l}\text { Do you use } \\
\text { mask? }\end{array}$ & $1252(83.5)$ & $247(16.5)$ \\
2 & $\begin{array}{l}\text { Do you use } \\
\text { hand }\end{array}$ & $1246(83.1)$ & $253(16.9)$ \\
& sanitiser? & & \\
3 & $\begin{array}{l}\text { How many } \\
\text { times do you }\end{array}$ & $1052(70.2)$ & $447(29.8)$ \\
& $\begin{array}{l}\text { wash your } \\
\text { hand? }\end{array}$ & & \\
4 & $\begin{array}{l}\text { How many } \\
\text { times do you }\end{array}$ & $746(49.8)$ & $753(50.2)$ \\
& $\begin{array}{l}\text { use hand } \\
\text { sanitizser? }\end{array}$ & & \\
5 & $\begin{array}{l}\text { Do you } \\
\text { maintain } \\
\text { social } \\
\text { distancing? }\end{array}$ & & \\
\hline
\end{tabular}

Of the total respondents, though $69.8 \%$ having the appropriate knowledge on mode of spreading of the virus, but of them, $73.5 \%$ having negative attitude towards use of face mask ( $\left.p=0.00 ; \chi^{2}=20.3\right)$. Similarly, $98.1 \%$ of the respondents knew that hand washing as preventive measure for contracting the disease but, of them $75.0 \%$ showed negative attitude towards it $\left(p>0.05 ; \chi^{2}=7.3\right)$.

Though $51.6 \%$ of the study population were equipped with adequate knowledge on preventive measures, but among them only $52.1 \%$ using face mask $(p>0.05), 51.8 \%$ practicing hand washing $(p>0.05), 57.5 \%$ using hand sanitiser $(p=0.00)$. Furthermore, $72.4 \%$ of the respondents having adequate knowledge on social distancing but $54.7 \%$ of them were not practicing social distancing $(p=0.00)$.

0.35-0.88, $p=0.01)$. Students had lower level of knowledge on social distancing, which was two times lesser than other professionals (OR: 2.3, 95\% CI: 1.73-3.09, $p=0.00)$. (table-IV)

Table-IV: Binary logistic regression on social distancing knowledge and sex, social distancing practice and occupation

\begin{tabular}{ccc}
\hline Characteristics & OR & $\begin{array}{c}\text { Lower- upper in } \\
95 \% \mathrm{CI}\end{array}$
\end{tabular}

\begin{tabular}{lccc}
\hline $\begin{array}{l}\text { Sex } \\
\text { (female/male) }\end{array}$ & 1.5 & $1.24-2.01$ & 0.00 \\
& & & \\
$\begin{array}{l}\text { Social } \\
\text { distancing } \\
\text { practice }\end{array}$ & 0.55 & $0.35-0.88$ & 0.01 \\
$\begin{array}{l}\text { Occupation } \\
\text { (students/other } \\
\text { professions) }\end{array}$ & 2.3 & $1.73-3.09$ & \\
& & & \\
& & & \\
\hline
\end{tabular}

Binary logistic regression model was constructed to assess the influence of gender and occupation on practice of social distancing. Model explains that more than $70.0 \%$ of respondents having social distancing knowledge. Male respondents had 1.5 times more knowledge about social distancing than female counterparts (OR: 1.5, 95\% CI: 1.24-2.01, $p=0.00$ ). Respondents having knowledge about social distancing, but $50.0 \%$ of the respondents did not practice social distancing (OR: $0.55,95 \% \mathrm{CI}$ : 


\section{Discussion}

This descriptive, cross sectional study was conducted among 1549 participants through online, self-administered and face to face interview. So far, this is the first study of its kind in Bangladesh assessing the knowledge, attitudes and practices towards COVID-19 among Bangladeshi population. Among the respondents, maximum (28.4\%) were from the $36-50$ years age group and $30.0 \%$ of the total completed their graduation, $29.0 \%$ were students.

Most of the study populations having the appropriate knowledge about the availability of the treatment, vaccine, mode of transmission and importance of quarantine period of the disease. These findings are consistent with the studies of Zhong BL et al conducted among the Chinese residents and of Alzoubi $\mathrm{H}$ et al conducted among the students in Jordan. ${ }^{15,16}$ Their knowledge regarding the availability of vaccines and treatment are also similar with other studies.

The findings of this study are the reflection of the effectiveness of the different awareness campaign conducted by the different agencies both in private and public sectors specially the health authorities in Bangladesh. This also supported by the positive attitude of the study population towards the measures including use of face mask, hand washing, use of hand sanitiser and social distancing.

Their sources of knowledge about KOVID-19 were television (14.3\%), social media (13.9\%), newspapers (13.5\%), advertisement in the newspapers (12.1\%); miking (11.9\%), handbill $(11.9 \%)$; friends, colleagues and relatives $(12.3 \%)$ and other sources (10.0\%). Importantly, among the study population 2 participant did not know about the COVID-19. Alzoubi $\mathrm{H}$ et al mentioned that the commonest source of knowledge of their participants was social media. ${ }^{16}$

Despite their knowledge, importantly, some $74.0 \%$ respondents thought that COVID-19 is a grave disease. This misconception actually leads them for the stigma towards the COVID-19 patients in the society, reflected in misbehave towards the COVID-19 affected neighbours even towards the frontline fighters including physicians, members of the law enforcing agencies and others who are engaged with prevention and control measures of COVID-19. It may be mentioned here some patients hide their travel details and even test results due to the stigma associated with being carriers of COVID-19 making the job of health workforce difficult and unsafe. Findings of other study conducted among university students in Jordan are inconsistent with this study. ${ }^{16}$

It was witnessed that an increase in stigmatization of people with symptoms of Covid-19. Widespread fears about the disease are causing people to behave inhumanely. ${ }^{17}$

These types of stigma also causing protest by the local people to bury the deceased in the earmarked graveyard in Dhaka and also in making a quarantine house in other part of the Dhaka city. There are also a few incidents of threatening of eviction from homes in different parts of the country.

Covid-19 positive patients across the world have reportedly suffered social stigma - hatred, xenophobia and denial of treatment. ${ }^{18}$

To combat the situation different government agencies including Anti Corruption Commission, Metropolitan Police, Electric Supply Authority and others warned the offender for their unlawful, inhuman activities towards the COVD-19 patients and the frontline fighters including health workforce, law enforcing agencies and others. The Directorate General of Health Services repeatedly is urging the people to be humane towards the COVID-19 patient or having the travel history. With these government efforts the situation has been improved significantly.

There are spread of panic and stigma across the country. The key reason behind the stigma and discrimination regarding COVID-19 in Bangladesh is little knowledge on the novel virus. Furthermore, this poor knowledge has been influenced by spread of rumours, fake news, falsehoods, nonspecific information etc. This finding is consistent with Hasan MT et al. ${ }^{19}$

Mass campaign with clear, complete and specific information is critical to prevent stigma and 
discrimination aimed at lowering the transmission of the virus.

It was to be found that in this study a number of socio demographic factors are associated with knowledge of different areas of COVID-19, which are important for the public health policy makers, media and the health workforce to identify the target population for the prevention and control of COVID-19. These findings are consistent with the study conducted in China during the rapid rise period of the disease, except the education level. Further, the health department of Bangladesh has been conducting RT-PCR tests in response to the request, only $10-12.0 \%$ of the test results are positive. $^{20}$ If the requesters identify the symptoms of COVID-19 more or less accurately, which will save the limited resources dedicated for diagnostic services.

Significant positive attitudes are evident towards the measures including use of face mask, hand washing maintaining social distancing, home quarantine are needed to prevent the transmission of the diseases or being affected by the virus.

Unfortunately, practices of these knowledge are significantly poor, which are reflected on the starting of the community transmission of the disease in the country. Findings of the study are some extent consistent with the other studies. ${ }^{15,16}$

Recent data show that $27 \%$ of the young age group are mostly contracted with coronavirus. ${ }^{21}$ In this study, it was to be found that students had lower knowledge on social distancing, which was two times lesser than other professions $(p=0.00)$. Furthermore, $50.0 \%$ of the total respondents did not practicing social distancing. These two factors might be the reason of large number of young people are being contracted with the coronavirus in Bangladesh. Studies showed that men and late adolescent are more likely to engage in risk-taking behaviours. Zhong BL et al also found in their study that there was significant association between male gender and potentially dangerous practices towards COVID-19. The dangerous practices among students could be ascribed to their young age, they mentioned..$^{15}$

Importantly, in this study, the knowledge level regarding different areas of COVID-19, except the symptoms was found to be high, and significantly associated with positive attitude towards prevention of the disease, but poorly associated with the appropriate practices. Zhong BL et al in their study found that the higher COVID-19 knowledge scores were significantly associated with negative attitudes and dangerous practices towards the epidemic. ${ }^{1}$ Knowledge and attitudes among the participants of the study of Alzoubi $\mathrm{H}$ et al in Jordan consistent with this study. ${ }^{16}$

Socio-demographic factors associated with the knowledge, attitude and practices towards COVID-19 are consistent with the previous studies. $^{12,15}$

Findings of this study clearly indicate the importance of improving health education with practical demonstration through both electronic and print media as well as engaging the health workers across the country. Importance of practices should be critically informed to the target audience. Academic institutions should also be involved in this initiative including their virtual sessions.

Strength of this study includes large sample size, with inclusion of a face to face interviewed a number of rural population, who did not access to internet and self-administered interviewed a number of city population of aged 50 years and above, which gives an opportunity to compare the findings among the groups. Furthermore, findings of this study regarding the KAP among the young age group could be generalised among the population of same socio-demographic characteristics across the country. It would be of help to develop public awareness programme, aimed to prevent and control the COVID-19. Limitations of the study included unstandardised and inadequate attitudes and practices measurements could be overcome with focus group discussion and in-depth interview.

\section{Conclusion}

Based on the study findings, it may be concluded that adequate knowledge and positive attitudes among the study population towards COVID-19, could be used to enhance appropriate practices for prevention and control of the epidemic.

As deficit of knowledge prevails particularly regarding the nature of the disease which leads to stigma needs to be eliminated from the society where the COVID19 patients and the frontline fighters live. Furthermore, 
inadequate knowledge regarding the symptoms of the disease may mislead them for COVID-19 test or to avail services at the health facilities, causing wastage of resources in a developing country like Bangladesh.

Public awareness campaign should be enhanced critically focusing the target audience to cover the knowledge gaps, motivation for appropriate practices and further improvement of attitudes towards prevention and control of the COVID-19 in the country are thus suggested. Moreover, further studies are suggested to assess the KAP towards the COVID-19 among the rural population, as limitations in representativeness of the rural sample.

Conflict of interest: None

Funding: None

Ethical approval: IRB of the Institute of Public Health, Dhaka

Submitted: $28^{\text {th }}$ June, 2020

Final revision received: $26^{\text {th }}$ July, 2020

Accepted: $30^{\text {th }}$ July, 2020

Published: $1^{\text {st }}$ August, 2020

\section{References}

1. WHO. Q\&A on coronaviruses (COVID-19). 9 March 2020. World Health Organization. https:/www. who.int/docs/default-source/ searo/ bangladesh/2019ncov/q-a-en.pdf?sfvrsn=275ce $4 d 2 \_6$

2. Rahman SMM, Hossain SM, Jahan MU. COVID-19 in Bangladesh: Measures for containment. Editorial, Bangladesh Med Res Counc Bull. 2020; 46:01-02

DOI: $10.3329 /$ bmrcb.v46i1.47460

3. Mackenzie JS. Smith DW. COVID-19: a novel zoonotic disease caused by a coronavirus from China: what we know and what we don't. Microbiology Australia 2020.

4. WHO. WHO Director-General's opening remarks at the media briefing on COVID-19 - 11 March 2020. World HO. Geneva. https://www.who.int/dg/speeches/ detail/who-director-general-s-opening-remarks-at-themedia-briefing-on-covid-19-11-march-2020.

5. Chowdhury MAJ. COVID-19 Pandemic and Bangladesh. Comment. Bangladesh Med Res Counc Bull. 2020; 46: 03-04

DOI: 10.3329/bmrcb.v46i1.47461
6. CDC. Coronavirus disease 2019 (COVID-19). 2020. [Online]. Centers for Disease Control. Atlanta, USA. https:/www.cdc.gov/coronavirus/2019-ncov/about/ transmission.

7. Jin YH, Cai L, Cheng ZS, Cheng H, Deng T, Fan $\mathrm{YP}$, et al. A rapid advice guideline for the diagnosis and treatment of 2019 novel coronavirus (2019$\mathrm{nCoV}$ ) infected pneumonia (standard version). Mil Med Res. 2020;7:4.

DOI: $10.1186 / \mathrm{s} 40779-0200233-6$

8. WHO. WHO Director-General's opening remarks at the mission briefing on COVID-19. 2020. [Online]. https://www.who.int/dg/speeches/ detail/who-directorgeneral-s-opening-remarks-at-the-mission

9. CDC. Centers for Disease Control. Atlanta, USA. People Who Are at Increased Risk for Severe Illness. https://www.cdc.gov/coronavirus/2019-ncov/needextra-precautions/people-at-increased-risk.html.

10. https://www.nationalgeographic.com/science/2020/ 07/why-do-asymptomatic-coronavirus-cases-evenhappen-cvd/

11. Ioannidis JPA. Coronavirus disease 2019: the harms of exaggerated information and non-evidence-based measures. Eur J Clin Invest. 2020:e13223.

DOI: $10.1111 /$ eci.13223

12. Giao H, Han NTN, Khanh TV, Ngan VK, Tam VV, An PL. Knowledge and attitude toward COVID-19 among healthcare workers at District 2 Hospital, Ho Chi Minh City. Asian Pacific Journal of Tropical Medicine. 2020; 13: 260-265

DOI: 10.4103/1995-7645.280396.

13. Mantwill S, Monestel-Umaña S, Schulz PJ. The relationship between health literacy and health disparities: a systematic review. PLoS One. 2015; 10: e0145455. [PMID:26698310]

DOI: 10.1371/journal.pone.0145455.

14. Wolf MS, Serper M, Opsasnick L, O'Conor RM, Curtis LM, Benavente JY et al. Awareness, attitudes, and actions related to COVID-19 among adults with chronic conditions at the on set of the U.S. Outbreak: A Cross-sectional Survey. 2020; April 9: M20-1239.

DOI: $10.7325 / \mathrm{M} 20-1239$

15. Zhong BL, Luo W, Li HM, Zhang Q-Q, Liu X-G, Li WT, Li Y. Knowledge, attitudes, and practices towards COVID-19 among Chinese residents during the rapid rise period of the COVID-19 outbreak: a 
quick online cross-sectional survey. International Journal of Biological Sciences. 2020; 16: 17451752.

DOI: $10.7150 / \mathrm{ijbs} .45221$.

16. Alzoubi H, Alnawaiseh N, Al-Mnayyis A, AbuLubad M, Aqe A, Hani Al-Shagahin H. COVID-19 - knowledge, attitude and practice among Medical and Non-Medical University students in Jordan. J Pure Appl. Microbiol. 2020;14, 17-24.

17. Hasan MT. The panic and the stigma. The Dhaka Tribune. $3^{\text {rd }}$ April, 2020.

https:/www. Dhaka tribune .com/opinion/oped/2020/04/03/the-panic-and-the-stigma)
18. Kamal RS. (Fear, hatred and stigmatization grip Bangladesh amid Covid-19 outbreak. The Business Standard 26 March, 2020, https://tbsnews.net/

19. M Tasdik Hasana, Sahadat Hossainb, Tanjir Rashid Saranc, Helal Uddin Ahmedd Addressing the COVID19 related stigma and discrimination: a fight against "infodemic" in Bangladesh. Research Gate. April 2020. https:/www.researchgate.net/publication/340923292.

20. IEDCR/DGHS. Reports on Covid-19. Institute of Epidemiology Disease Control and Research. Dhaka, Bangladesh. www.iedcr.gov.bd

21. DGHS. Reports on COVID-19. Directorate General of Health Services. Dhaka Bangladesh. www. dghs.gov.bd 